\title{
Avaliação microestrutural de ligas de Al com introdução de Nb
}

\author{
Microstructural evaluation of $\mathrm{Al}$ alloys with $\mathrm{Nb}$ introduction
}

Kelly dos Santos Marinho"* Antonio Jorge Abdalla²

\section{RESUMO}

Analisou-se a modificação da microestrutura de ligas de alumínio que simulam sucata, pela adição de nióbio, promissor para o refino de grãos. Foram utilizadas ligas de alumínio contendo 7\% de silício e o teor de nióbio variou de 0,01\% a 1\%. Houve redução no tamanho médio do grão encontrado para cada condição do percentual de nióbio até 0,05\% de Nb, mas não para valores superiores. Há um pequeno aumento no valor da dureza pela adição de nióbio.

Keywords: Ligas AISi, Análise microestrutural, Dureza, Nióbio.

\section{ABSTRACT}

The modification of the microstructure of aluminum alloys that simulate scrap was analyzed by the addition of niobium, promising for grain refining. Aluminum alloys containing $7 \%$ silicon were used and the niobium content varied from $0.01 \%$ to $1 \%$. There was a reduction in the average grain size found for each condition of the percentage of niobium up to $0.05 \% \mathrm{Nb}$, but not for higher values. There is a small increase in the hardness value by adding niobium.

Palavras-chave: AISi alloys, Microstructural analysis, Hardness, Niobium. 


\section{INTRODUÇÃO}

O alumínio (Al) e suas ligas compõem um dos conjuntos de materiais metálicos mais versáteis, econômicos e atrativos para uma ampla gama de aplicações. O alumínio possui uma baixa densidade e boa resistência mecânica, fato que o torna bastante útil na construção de estruturas móveis, como veículos e aeronaves. Outra característica interessante do alumínio é a sua resistência à oxidação progressiva, já que sua superfície reage com o oxigênio da atmosfera, formando uma camada de óxido protetor que impede a progressão da deterioração do material.

Dada a importância das ligas de alumínio para o setor aeroespacial e automotivo, melhorar o desempenho das ligas, torna-se um desafio crescente. Há também o "alumínio secundário", produzido a partir da reciclagem de sucata, contendo uma quantidade relativamente elevada de impurezas de ferro ( $\mathrm{Fe})$, para a obtenção de ligas com propriedades melhores.

Assim, este trabalho analisou a microestrutura das ligas de alumínio, simulando ligas vindas da sucata, de menor custo, modificando as microestruturas com a introdução do elemento nióbio ( $\mathrm{Nb}$ ), o que é incomum, pois este é promissor para refinar grãos.

\section{FUNDAMENTAÇÃO}

O alumínio e suas ligas são caracterizados por uma densidade relativamente baixa $\left(2,7 \mathrm{~g} / \mathrm{cm}^{3}\right.$, em comparação com uma densidade de $7,9 \mathrm{~g} / \mathrm{cm}^{3}$ para o aço), condutividades elétrica e térmica elevadas, resistência à corrosão em alguns ambientes comuns, incluindo a atmosfera ambiente.

Atualmente, as ligas de alumínio têm grande importância na aplicação em engenharia na área de transporte como, por exemplo, aeronaves. Devido a sua baixa densidade, a produção de ligas com maior resistência irá representar redução no peso de veículos levando à redução no consumo de combustíveis. Ligas de alumínio geralmente incluem o cobre, o magnésio, o silício, o manganês e o zinco, porém, não nióbio, no qual se espera haver um refinamento dos grãos e aumento de suas propriedades mecânicas ${ }^{1,2}$.

\section{MATERIAIS E MÉTODOS}

Foram utilizadas ligas de alumínio, simulando as produzidas a partir da reciclagem de sucata, ou seja, liga de baixa pureza, contaminada principalmente com ferro, que ocasiona fragilidade ao material. Com uma visão econômica, adicionou-se nióbio em uma liga de alumínio contendo 7\% de silício (Si) para contrabalancear os malefícios gerados pelo ferro e melhorar as propriedades no material.

Inicialmente, foram preparadas ligas de AlSi com diferentes teores de nióbio, variando de 0,01\% a 1\% de nióbio, além da liga sem nióbio. Estas ligas foram fundidas no Instituto Tecnológico de Aeronáutica (ITA) a partir de pré-ligas produzidas e cedidas pela Companhia Brasileira de Metalúrgica e Mineração (CBMM).

A preparação das amostras para as análises metalográficas passaram pelos seguintes procedimentos:

- Embutimento a quente: A finalidade do embutimento foi facilitar o manuseio durante o preparo das amostras, evitando os cantos vivos das amostras e facilitando o trabalho de lixamento e polimento. As amostras foram preparadas por meio de prensas, aplicando pressão e aquecimento. As amostras foram posicionadas com a face que se quer analisar em contato com o êmbolo inferior da máquina de embutimento. A resina de baquelite foi colocada na câmera de embutimento pressionando-a por 10 minutos, posteriormente, a amostra foi resfriada em água.

- Lixamento: Para o lixamento das amostras das ligas de alumínio, foram utilizadas lixas ligadas em discos rotativos. Inicialmente, utilizou-se a lixa de granulometria 220 mesh, aumentando-se gradativamente até 1.200 mesh. Após o lixamento foi avaliada a dureza por microindentação.

- Polimento: As amostras das ligas de alumínio foram polidas até que a superfície tivesse espelhada e sem nenhum arranhado. Esta etapa foi executada com uma politriz metalográfica e suspensão de alumínio com granulometria de 1 e $0,5 \mu \mathrm{m}$.

- Ataque químico: $\mathrm{O}$ ataque químico teve a finalidade de evidenciar a microestrutura e os constituintes da amostra, proporcionando maior compreensão das características microestruturais. Os reagentes utilizados estão apresentados na Tabela 1. Inicialmente, o material foi atacado pelo reagente químico Poulton, como algumas amostras ficaram escuras após efetuar este ataque, foi utilizado um novo ataque como clareador com o intuito de melhorar a visualização das microestruturas das ligas de alumínio. 
Tabela 1: Composição química dos ataques utilizados nas amostras

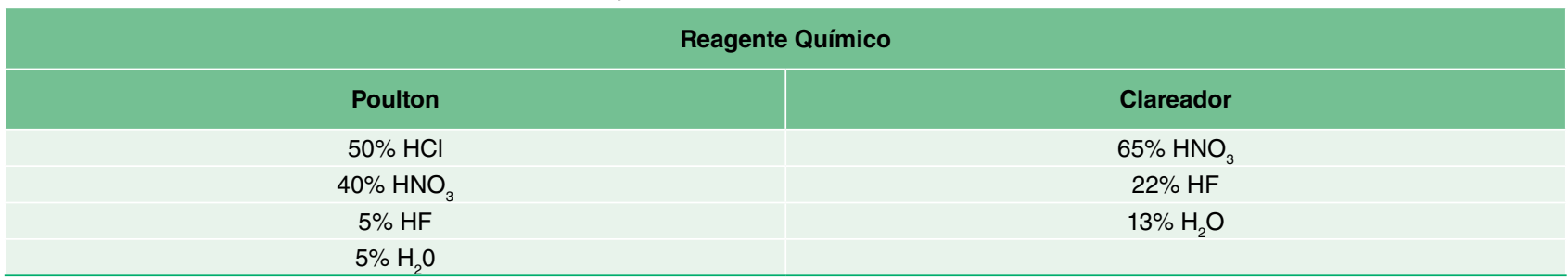

- Tamanho dos grãos: $\mathrm{O}$ tamanho médio do grão foi um critério utilizado para avaliar o efeito do nióbio sobre as ligas. As propriedades mecânicas dos materiais metálicos, como limite de escoamento, resistência à tração, dureza, entre outras, tem relação com o tamanho do grão.

- Imagens: Após os ataques químicos as imagens foram analisadas por microscopia óptica com a utilização de filtro diferencial com interferência (DIC). As imagens foram capturadas com aumentos de 25 a 100 vezes para permitir a avaliação no tamanho dos grãos.

- Método de contagem de grãos: Deve evidenciar que o cruzamento entre a linha teste e o contorno do grão é chamado de 'intersecção'. Enquanto que o segmento da linha padrão que atravessa o grão é denominado como 'intercepto'. Por este método, foram traçadas retas paralelas e perpendiculares, formando uma grade sobre a micrografia, a seguir, foi calculado o número de vezes que as linhas cortam as bordas dos grãos. O diâmetro médio do grão pode ser calculado pela equação abaixo chamada de Método de interceptos de Heyn (Eq. 1), posteriormente, foram calculados a média e o desvio padrão pelas Eqs. 2 e 3, respectivamente (ASTM E112-95).

$$
\begin{aligned}
& \overline{\boldsymbol{l}}=\frac{\boldsymbol{l}}{\boldsymbol{n} \cdot \boldsymbol{x}} \\
& \overline{\boldsymbol{x}}=\frac{\Sigma x i}{n} \\
& \boldsymbol{d} \boldsymbol{p}=\sqrt{\frac{\sum x(-\bar{x})}{n}}
\end{aligned}
$$

onde:

$\bar{l} \bar{l}$ : comprimento médio do intercepto; l: comprimento do seguimento; n: número de interceptos; $\mathrm{x}$ : aumento utilizado; $\overline{\boldsymbol{x}} \overline{\boldsymbol{x}}$ média; e dp: desvio padrão.

Neste artigo, foi utilizado o método dos interceptos que equivale a aplicar várias linhas sobre a microestrutura de um material. Para facilitar a visualização, os contornos dos grãos foram destacados, conforme modelo apresentado na Fig. 1.

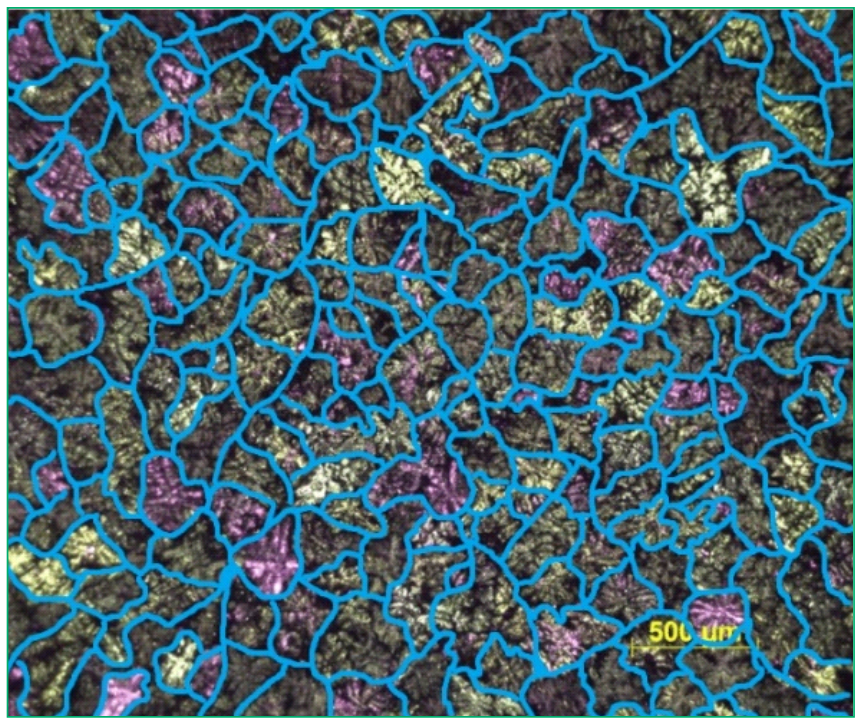

Figura 1: Microestrutura da Liga AISi, com $0,1 \% \mathrm{Nb}$, destacando os contornos de grão. 
Foram feitas cinco linhas em cada microestrutura para a contagem do número de grãos interceptados. Depois, o método de Heyn foi utilizado para calcular o tamanho médio dos grãos. Para calcular o tamanho das linhas, diretamente sobre a imagem, foi utilizada a barra de aumento da própria figura.

- Dureza: testes de dureza Vickers foram efetuados por microindentação.

\section{RESULTADOS E DISCUSSÕES}

As imagens das Figs. 2 e 3 ilustram o tipo de microestrutura obtida após o ataque químico. Nota-se que, ao comparar as estruturas da Fig. 2, sem nióbio, com as estruturas da Fig. 3, com $0,02 \%$ Nb, houve uma redução no tamanho dos microconstituintes, mostrando a eficácia da inclusão do elemento nióbio na microestrutura. Imagens semelhantes foram obtidas para todas as ligas com as diferentes porcentagens de $\mathrm{Nb}$ introduzidas.

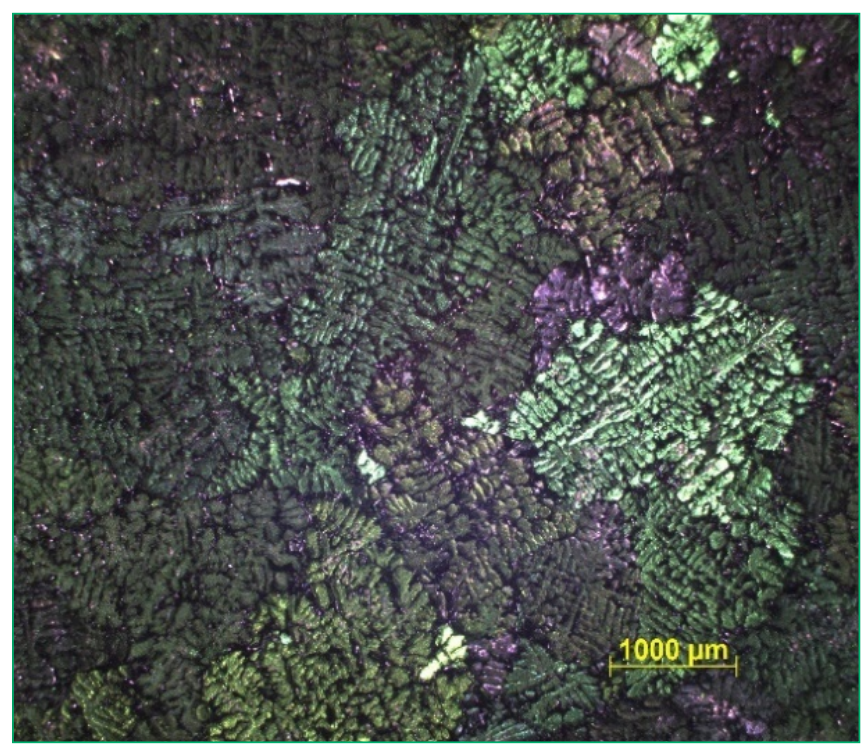

Figura 2: M.O. Liga AlSi sem $\mathrm{Nb}$

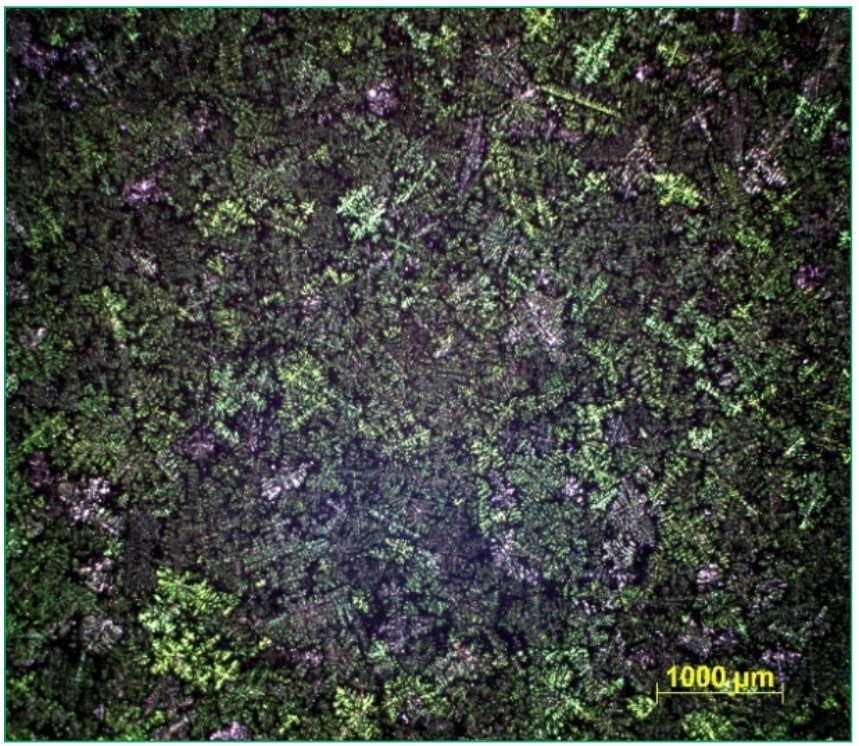

Figura 3: M.O. Liga AISi $-0,02 \% \mathrm{Nb}$.

As Figs. 4 e 5 mostram as linhas traçadas em duas imagens para ilustrar o processo realizado para o cálculo dos tamanhos dos grãos. É necessário perceber quantos traços existem sobre a imagem e quantos grãos são cortados em cada uma das imagens. $\mathrm{O}$ tamanho dos grãos resulta na contagem do número de vezes que uma linha retilínea encontra os contornos dos grãos. Linhas paralelas aleatórias foram sobrepostas sobre cada imagem: 


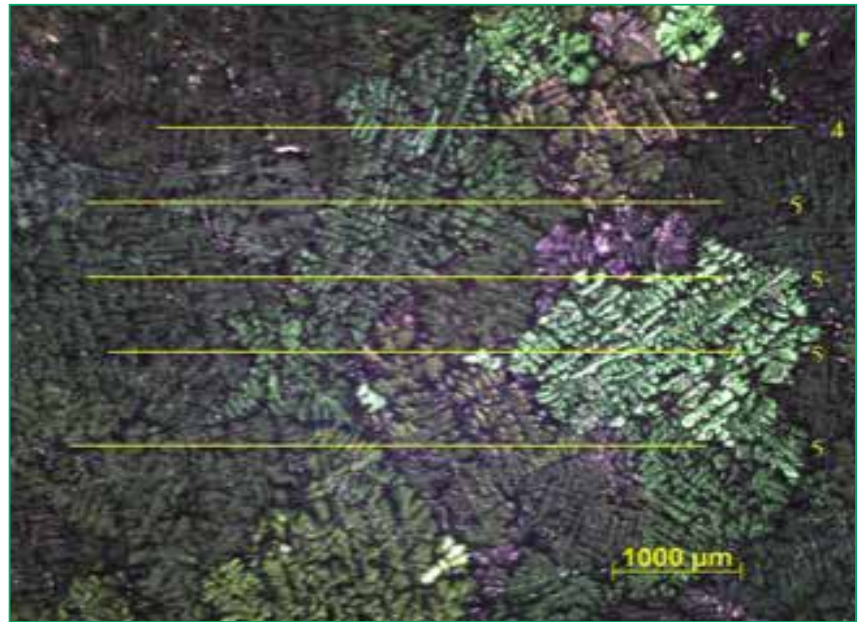

Figura 4: Linhas de intercepto: liga AISi sem Nb.

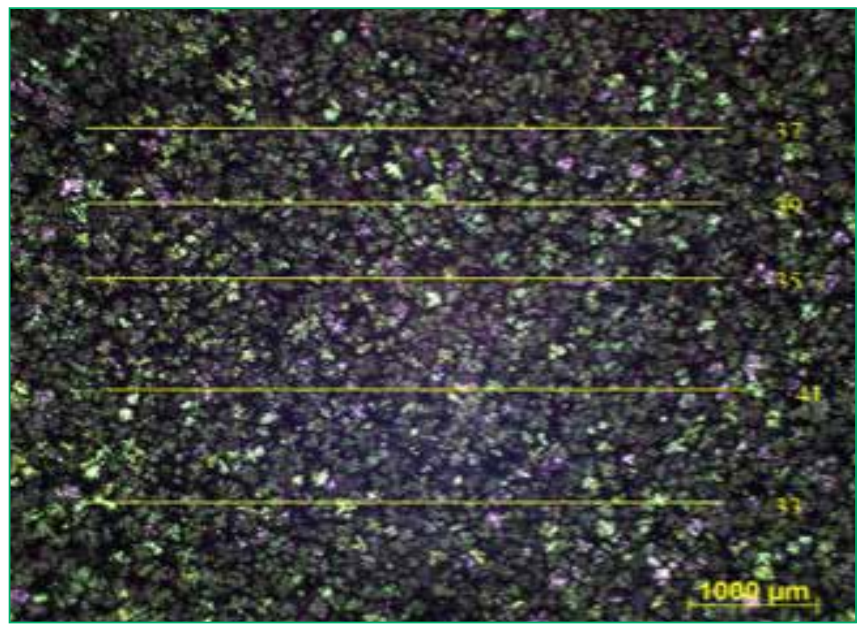

Figura 5: Linhas de intercepto: liga AlSi com $0,05 \% \mathrm{Nb}$.

A Tabela 2 mostra o tamanho médio do grão encontrado para cada condição estudada do percentual de nióbio, que varia desde $0 \%$ até $1 \%$. Nota-se que ao se aumentar a porcentagem de $\mathrm{Nb}$, há a redução no tamanho médio do grão. A influência parece ter maior importância até $0,05 \%$ de $\mathrm{Nb}$, um valor superior a este parece não ter influência adicional para reduzir o tamanho do grão. Há pouca alteração após $0,05 \%$ de $\mathrm{Nb}$, tornando o tamanho do grão constante, em torno de $200 \mu \mathrm{m}$.

Tabela 2: Média do tamanho de grão (um) em função da adição de $\mathrm{Nb}$

\begin{tabular}{|c|c|}
\hline Nb & Clareador \\
\hline $0,00 \%$ & $1.352 \pm 359$ \\
\hline $0,02 \%$ & $567 \pm 123$ \\
\hline $0,05 \%$ & $178 \pm 35$ \\
\hline $0,10 \%$ & $204 \pm 31$ \\
\hline $0,20 \%$ & $253 \pm 39$ \\
\hline $0,50 \%$ & $181 \pm 13$ \\
\hline $1,00 \%$ & $227 \pm 88$ \\
\hline $0,20 \%$ & $253 \pm 39$ \\
\hline & $227 \pm 88$ \\
\hline
\end{tabular}

Na Tabela 3 são mostrados os valores de dureza Vickers observados para as amostras estudadas. Nota-se que há um pequeno aumento no valor da dureza, devido à elevação nos percentuais do elemento nióbio. 
Tabela 3: Média e desvio padrão das medidas feitas de dureza por microindentação.

\begin{tabular}{|c|c|c|}
\hline $\begin{array}{c}\text { Amostras } \\
\text { (\% de nióbio) }\end{array}$ & $\begin{array}{c}\text { Dureza } \\
\text { (HV) }\end{array}$ \\
\hline 0,01 & 58 & 5 \\
\hline 0,02 & 57 & 6 \\
\hline 0,05 & 67 & 5 \\
\hline 0,10 & 65 & 3 \\
\hline 0,20 & 61 & 3 \\
\hline 0,50 & 73 & 2 \\
\hline 1,00 & 67 \\
\hline
\end{tabular}

\section{CONCLUSÃO}

Neste trabalho, foram utilizadas ligas de alumínio produzidas de forma a reproduzir as ligas vindas de reciclagem de sucata (contaminadas por Fe), introduzindo diferentes teores de nióbio nas ligas, promissor para refinar os grãos, para a obtenção de ligas com propriedades mecânicas superiores.

A menor redução no tamanho de grão foi observada para o acréscimo de $0,05 \%$ de $\mathrm{Nb}$, não sendo observado reduções para valores mais altos. Foi observada pouca elevação nos valores de dureza.

São necessários mais estudos para avaliar outras propriedades importantes para as ligas, como a morfologia dos precipitados formados de AlSiFe e a ductilidade do material.

\section{AGRADECIMENTOS}

Agradeço ao meu coordenador, Antônio Jorge Abdalla, ao IEAV, ao ITA, ao Pibic/CNPQ e a CBMM pela colaboração na pesquisa realizada.

\section{REFERÊNCIAS}

1. Fridlyander IN, Sister VG, Grushko OE, Berstenev VV, Sheveleva LM, Ivanova1 LA. Aluminum alloys: promising materials in the automotive industry. Metal Science and Heat Treatment. 2002; 44(9-10):365-70. https://doi.org/10.1023/A:1021901715578

2. Rana RS, Purohit R, Das S. Reviews on the influences of alloying elements on the microstructure and mechanical properties of aluminum alloys and aluminum alloy composites. International Journal of Scientific and Research Publications. Jun. 2012;2(6):1-7. Disponível em: http:// www.ijsrp.org/research_paper_jun2012/ijsrp-June-2012-10.pdf

3. Mohamedi M, Kawaguchi N, Sato Y, Yamamura T. Electrochemical study of the mechanism of formation of the surface alloy of aluminumniobium in LiCl-KCl eutectic melt. Journal of Alloys and Compounds. 1999; 287(1-2):91-7. https://doi.org/10.1016/S0925-8388(99)00020-1

4. Elliott RP, Shunk FA. The Al-Nb system (Aluminum-Niobium). Bulletin of Alloy Phase Diagrams. 1981; 2:75-81. https://doi.org/10.1007/ BF02873708

5. Chandrashekar T, Muralidhara MK, Kashyap KT, et al. Effect of growth restricting factor on grain refinement of aluminum alloys. Int $\mathrm{J}$ Adv Manuf Technol. 2009; 40:234-41. https://doi.org/10.1007/s00170-007-1336-x

6. Tiryakioglu M, Campbell J, Alexopoulos ND. Quality Indices for Aluminum Alloy Castings: A Critical Review. Metall and Materi Trans B. 2009; 40:802. https://doi.org/10.1007/s11663-009-9304-5

7. ASTM E112-95. Standard Test Methods for Determining Average Grain Size, 1995. 